\title{
Telemedicine and Toxicology: Back to the Future?
}

\author{
Fred Fung
}

Published online: 27 November 2013

(C) American College of Medical Toxicology 2013

Letter to the Editor:

I read the Editorial piece entitled "Telemedicine and Toxicology: Back to the Future" by Dr. Skolnik with interest (J. Med. Toxicol. (2013) 9:217-219). Dr. Skolnik presents a strong case that we as toxicologists need to "re-stake" our claim on telemedicine. I agree. I personally practice telemedicine within the confine of our medical institution in which a secured patient portal and HIPAA-compliant virtual environment are used to "see" patients with selected medical conditions, agreed and approved by our Telehealth Committee. While patients and physicians benefit from the availability of telemedicine in terms of patient satisfaction, access to care, and ease to specialty care consultation, there are several issues worth consideration:

1. Privacy, security, and patient confidentiality

Medical toxicologists who participate in telemedicine have the same duty and obligation for the privacy and security of patient information as providing face-to-face care under the rules of HIPAA, HITECH Act, and specific state law. For example, using Skype or Smartphone at its current platform is not HIPAA compliant.

2. Credentialing, standards of care, and malpractice risks

Health care entities must ensure that telemedicine providers who are credentialed on the staff of a different

\section{F. Fung $(\bowtie)$}

Occupational Medicine, Sharp HealthCare, Sharp Rees-Stealy

Medical Group, 2001 Fourth Ave., San Diego, CA 92101, USA

e-mail: fred.fung@sharp.com

\section{F. Fung}

Medical Toxicology Fellowship, University of California San Diego,

La Jolla, CA, USA

F. Fung

Division of Occupational Medicine, Department of Medicine,

University of California at Irvine, Irvine, CA, USA

entity or licensed by another state or country are legally permitted to provide services to the receiving entity's patients. While state statutes do not expressly create different standards of care for health care services provided via telemedicine, medical toxicologists should be aware of the unique standard of care issues that telemedicine activities could present, depending on the nature of services being provided via telemedicine. Courts would almost invariably find that a physician who treats a patient in a state, via telemedicine, is subject to that state's laws. Courts have yet to offer much guidance on the legal parameters of acceptable multistate telemedicine practice involving prescription medications, but the Hageseth opinion has set the tone for what may be on the horizon (Hageseth v. Superior Court of San Mateo County (2007) 150 Cal.App.4th 1399, 59 Cal.Rptr.3d 385.). The California appellate court in Hageseth allowed California to criminally prosecute a Colorado-licensed physician for the unlicensed practice of medicine in California through telemedicine.

3. Informed consent

Patients must be aware of and consent to the potential benefits and risks associated with telemedicine, including delays that could result from deficiencies or failures of telecommunications equipment and the potential for security breaches. Some states such as California have more relaxed regulations, while others may have heightened requirements.

4. Maintaining continuity of care

Documentation of telemedicine encounters must be included in the ongoing medical record of the patient. This documentation ensures an accurate and complete patient history that can be referenced by subsequent physicians. For example, California law expressly requires physician to fully document and memorialize all other details of a telemedicine interaction in the patient's 
medical record, as the physician would for any other type of health care interaction with the patient. Medical toxicologists should also be aware of the application of this medical record documentation requirement when collaborating with other health care practitioners, entities, or facilities on telemedicine ventures because the law applies to almost any health care entity, facility, or person who has responsibility for decisions respecting the health care of others.

Conflict of interests None. 